\title{
RARE PRESENTATION OF MELORHEOSTEOSIS INVOLVING CARPAL BONES
}

\author{
B. V. Ramana ${ }^{1}$, Y. Srinivas², M. V. Reddy ${ }^{3}$, Harshad Jawalkar ${ }^{4}$, Guruvardhan Kumar ${ }^{5}$
}

\section{HOW TO CITE THIS ARTICLE:}

B. V. Ramana, Y. Srinivas, M. V. Reddy, Harshad Jawalkar, Guruvardhan Kumar. "Rare Presentation of Melorheosteosis Involving Carpal Bones". Journal of Evolution of Medical and Dental Sciences 2014; Vol. 3, Issue 08, February 24; Page: 1872-1875, DOI: 10.14260/jemds/2014/2072

ABSTRACT: Melorheostosis is a rare sclerosing bone dysplasia, known as Leri disease characterized by a "flowing" hyperostosis of the cortex. Classically, melorheostosis affects the long bones of the skeleton, especially those in the lower extremities. Involvement of wrist is rare. The radiographic appearance has been likened to "dripping wax down the side of a candle." The clinical and the radiographic manifestations of melorheostosis have been encountered in a 12-year-old male child. Examination revealed limitation of movements of right wrist. Conventional radiographs of right hand showed increase in density of scaphoid, lunate, Triquetrum and Pisiform, skeletal survey showed isolated carpal involvement, 3D CT scanning showed patchy increase of density with cortical dripping appearance of carpal bones.

KEYWORDS: Melorheostosis, wrist, carpal bones, candle wax appearance.

INTRODUCTION: Two French neurologists, Leri and Joanny (1922) published the first case in which an arm was affected, and suggested the descriptive title melorheostosis ${ }^{1}$. It is a rare dysplasia where hereditary and familial influences play no part in this affection. Unlike most of the other osteosclerotic dysplasias, melorheostosis is not believed to be a genetic disorder. Its prevalence is estimated at one per million. ${ }^{2}$ It usually involves the periosteum and endosteum of diaphyseal cortical bone. There is a peculiar tendency for the hyperostosis to involve only one side the bone, following a sclerotomal pattern. ${ }^{2}$ It is characterized radiologically, by the appearance in the long bones of "melting wax flowing down a candle". This appearance is the result of longitudinal bars of hyperostosis along single or contiguous bones.

Classically, melorheostosis affects the long bones of the skeleton, especially those in the lower extremities $^{3}$. Based on the extension of the lesion bone involvement may be monostotic, polyostotic or monomelic. It may occur in association with other types of sclerosing bone dysplasias such as osteopoikilosis and osteopathia striata ${ }^{4}$ and with tumor-forming disease such as tuberous sclerosis and neurofibromatosis. ${ }^{5}$ Vascular lesions associated with melorheostosis include hemangiomas, vascular nevi, varices, glomous tumors, arteriovenous malformations and aneurysms ${ }^{6}$. The age of presentation ranges from the neonatal period to the elderly. The disease usually becomes apparent in childhood or adolescence with a peak between the ages 5 and $20 . .^{7}$ There are no gender differences or any difference with respect to ethnicity. ${ }^{7}$

The etiology remains unknown. Two main theories have been proposed. The "classic theory" claims the presence of an early embryonic infection of a sensory nerve inducing changes in the respective sclerotome. The second is the concept of "Mosaicism" which better explains the sporadic occurrence, the asymmetric "segmental" pattern with variable extent of involvement and equal gender ratio of the disease. ${ }^{7}$ The classic radiographic finding is asymmetric, irregular osteosclerosis along the long axes of the long bones. In children the sclerosis in the long bones is endosteal, whereas 
in adults it is subperiosteal or extra cortical. ${ }^{2}$ The clinical course of melorheostosis is one of slow but constant progression into adult. ${ }^{2}$

CASE REPORT: We describe a 12-year-old boy presented with difficulty in using his right hand since birth and on and off pain in right wrist. Clinical examination revealed limitation of dorsi flexion and palmar flexion of right wrist. There was a full range of motion in elbow and all joints of fingers. There were no contractures or any deformities. There was no atrophy of muscles and sensibility is normal. There were no signs of inflammation. There was no evidence of neurofibromas or aneurysms.

Conventional radiographs of the right hand showed sclerosis of scaphoid, lunate, Triquetrum and Pisiform skeletal survey showed isolated involvement of carpal bones.

3D CT scan revealed increase in thickness of bone with candle wax like appearance.

Blood biochemistry, including complete blood count, erythrocyte sedimentation rate, Creactive protein, serum calcium, phosphorous and alkaline phosphatase levels were normal.

Patient was kept on a regimen of non-steroidal anti-inflammatory medication and was given physiotherapy with wax bath and gentle assisted mobilization.

DISCUSSION: Melorheostosis is a rare hyperostotic, benign, sclerosing bone dysplasia. The etiology of melorheostosis remains unknown. The age of presentation ranges from the neonatal period to the elderly. The disease usually becomes apparent in childhood or adolescence. The presenting signs and symptoms of this condition are variable depending on the age of patient. Adults typically present with pain, joint stiffness, or a progressive deformity, while presentation in a child would more likely be as limb length discrepancy, deformity, or joint contractures which may also be seen before radiographic evidence of any bony changes. ${ }^{8}$ Melorheostosis affects the long bones of the skeleton, especially those in the lower extremities than upper extremities. In the upper limb also hand and isolated carpal involvement is rare. Symptoms of pain and tenderness have been common complaints in the majority of cases resulting from melorheostosis of hand, and although there are many theories regarding the etiology of pain, the cause of pain associated with is not known. Fibrosis of skin and soft tissues and joint contractures described in other patients ${ }^{7}$ were not present in this patient.

The diagnosis of melorheostosis is usually made by the classical conventional radiographic findings. The pattern of bony changes are variable, and there have been five patterns identified radio graphically which include osteoma-like pattern(30\%), classic candle wax appearance(22\%), myositis ossificans-like pattern(4\%), osteopathia striata-like(26\%), and mixed pattern(18\%). The anatomic distribution is as follows: upper limb (22\%), lower limb (70\%), upper and lower extremities (4\%), and axial skeleton (4\%).7 Intra articular extension of the lesion and mineralization leads to stiffness and restriction of joint mobility in these patients. CT and MRI are not routinely needed but will show cortical extent of the lesion, demarcation between normal and abnormal bone and better delineate the soft tissue finding. The clinical course of melorheostosis is one of slow but constant progression into adult.

Osteomyelitis, osteopetrosis, osteopoikilosis, and osteopathia striata should all be considered in the differential diagnosis, 9,10 but the most important differential diagnosis of melorheostosis is bone tumors producing dense bone, primarily the various types of osteosarcoma. Considering all of these conditions, the overall clinical, radiographic features do not fit our patient. 
There is no specific treatment for melorheostosis. Generally, emphasis is placed on conservative measures such as pain control with non-steroidal anti-inflammatory drugs and physiotherapy. There seemed to be a connection between severity of pain and extent of hyperostosis especially in the bone marrow compartment, perhaps due to an elevated intra-osseous pressure resulting from hindered blood circulation. Preservation of joint motion is an important aim. Some authors suggest early training to use the unaffected extremity. In the present patient physiotherapy and simple non-steroidal anti-inflammatory medication was effective in managing symptoms.

\section{REFERENCES:}

1. Leri A, Joanny J. Une affectione non decrite des os Hyperostose 'en coulee' sur toute la longeur d'un member our 'melorheosteose'. Bull mem soc med Hop Paris. 1922; 46:1141.

2. John A. Herring. Tachdjian's paediatric orthopaedics $3^{\text {rd }}$ ed. Vol 3. 2002; p: 1559-1561.

3. Garver P, Resnick D, Haghighi P, Guerra J Jr. Melorheostosis of the axial skeleton with associated fibrolipomatous lesions. Skeletal Radiol 1982. 9:41-44.

4. De Keyser J, Bruiland M, De Greeve J, Leemans J, Potvliege R, Six R, Ebniger G. Osteopathia striata with cranial sclerosis. Clin Neurol Neurosurg 1983. 85:41-48.

5. Roger D, Bonnetblanc JM, Leroux-Robert C. Melorheostosis with associated minimal change nephritic syndrome, mesenteric fibromatosis and capillary haemangiomas. Dermatology 1994. 188:166-168.

6. Arbuckle HA, Morelli JG. Pigmentary disorders: update on neurofibromatosis and tuberous sclerosis. Curr Opin Paediatr 2000. 12:354-358.

7. Freyschmdt J. Melorheostosis: A review of 23 cases. Eur Radiol. 2001; 33:328-31.

8. Gossler C, Kall C, Christopoulos G, Prommerberger KJ. Melorheostosis of the hand. A case report. Hand Chir Mikro Chir Plast Chir. 2001; 33:328-31.

9. Fernandes $\mathrm{CH}$, Matheus RP, Faloppa F, Albertoni WM. Alteracoes esqueleticas da mao na picnodisostose. Rev Bras Orthop1996; 31:441-2.

10. Judkiewicz AM, Murphy MD, Resnik CS, Newberg AH, Temple HT, Smith WS. Advanced imaging of melorheostosis with emphasis on MRI. Skeletal Radiol. 2001; 30:447-53.
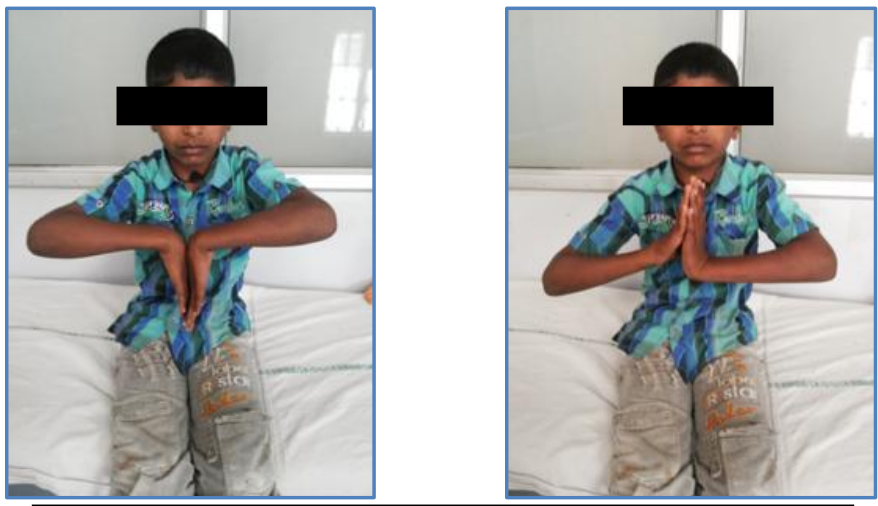

Fig. 1a \& 1b: Clinical Photographs showing limitation of movements of right wrist 


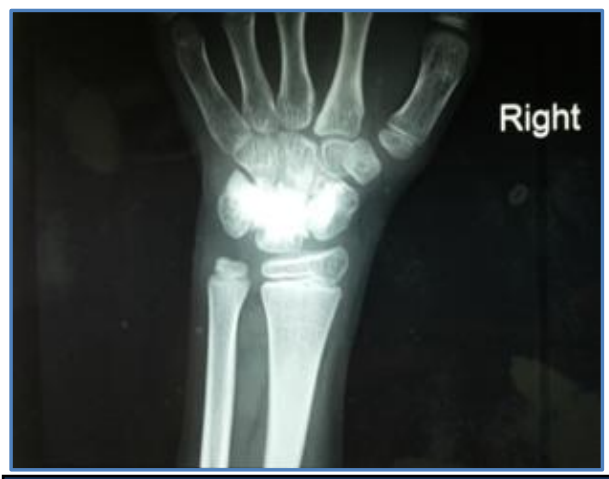

\section{Fig. 2: Radiograph of right wrist}

\section{AUTHORS:}

1. B. V. Ramana

2. Y. Srinivas

3. M. V. Reddy

4. Harshad Jawalkar

5. Guruvardhan Kumar

\section{PARTICULARS OF CONTRIBUTORS:}

1. Professor, Department of Orthopaedics, Kamineni Institute of Medical Sciences, Narketpally, Nalgonda, A.P.

2. Assistant Professor, Department of Orthopaedics, Kamineni Institute of Medical Sciences, Narketpally, Nalgonda, A.P.

3. Professor, Department of Orthopaedics, Kamineni Institute of Medical Sciences, Narketpally, Nalgonda, A.P.
4. Assistant Professor, Department of Orthopaedics, Kamineni Institute of Medical Sciences, Narketpally, Nalgonda, A.P.

5. Assistant Professor, Department of Orthopaedics, Kamineni Institute of Medical Sciences, Narketpally, Nalgonda, A.P.

\section{NAME ADDRESS EMAIL ID OF THE CORRESPONDING AUTHOR:}

Dr. B. V. Ramana,

No. 523, Manasarovar HT3,

Trimulghery,

Secunderbad - 500009,

Andhra Pradesh.

E-mail: bjvramana@gmail.com

Date of Submission: 24/01/2014.

Date of Peer Review: 26/01/2014.

Date of Acceptance: 06/02/2014.

Date of Publishing: 19/02/2014. 